\title{
Delayed NK Cell Reconstitution and Reduced NK Activity Increased the Risks of CMV Disease in Allogeneic-Hematopoietic Stem Cell Transplantation
}

\author{
Ki Hyun Park ${ }^{1}$, Ji Hyeong Ryu ${ }^{2}{ }^{\infty}$, Hyunjoo Bae ${ }^{1}$, Sojeong Yun ${ }^{1}$, Joo Hee Jang ${ }^{1}$, Kyungja Han ${ }^{2}$, \\ Byung Sik Cho ${ }^{3}$, Hee-Je Kim ${ }^{3, *}{ }^{-1}$, Hyeyoung Lee ${ }^{4}$ and Eun-Jee $\mathrm{Oh}^{2, *(1)}$ \\ 1 Department of Biomedicine \& Health Sciences, Graduate School, The Catholic University of Korea, \\ Seoul 06591, Korea; neojk11004@naver.com (K.H.P.); jaydcom8673@gmail.com (H.B.); \\ dbsthwjd789@naver.com (S.Y.); eertrqjjhyu4@naver.com (J.H.J.) \\ 2 Department of Laboratory Medicine, Seoul St. Mary's Hospital, College of Medicine, The Catholic \\ University of Korea, Seoul 06591, Korea; hyesungsee@naver.com (J.H.R.); hankja@catholic.ac.kr (K.H.) \\ 3 Department of Hematology, Catholic Hematology Hospital, Seoul St. Mary's Hospital, College of Medicine, \\ The Catholic University of Korea, Seoul 06591, Korea; cbscho@catholic.ac.kr \\ 4 Department of Laboratory Medicine, Catholic Kwandong University International St. Mary's Hospital, \\ Incheon 22711, Korea; shomermaid@catholic.ac.kr \\ * Correspondence: cumckim@catholic.ac.kr (H.-J.K.); ejoh@catholic.ac.kr (E.-J.O.); \\ Tel.: +82-2-2258-1641 (E.-J.O.)
}

Received: 15 April 2020; Accepted: 20 May 2020; Published: 22 May 2020

\begin{abstract}
Cytomegalovirus (CMV) infection has a significant impact in patients after allogeneic hematopoietic stem cell transplantation (HSCT). We investigated natural killer (NK) cell reconstitution and cytotoxic/cytokine production in controlling CMV infection, especially severe CMV disease in HSCT patients. Fifty-eight patients with acute myeloid leukemia (AML) who received allo-HSCT were included. We monitored NK reconstitution and NK function at baseline, 30, 60, 90, 120, 150, and 180 days after HSCT, and compared the results in recipients stratified on post-HSCT CMV reactivation $(n=23)$, non-reactivation $(n=24)$ versus CMV disease $(n=11)$ groups. The CMV disease group had a significantly delayed recovery of CD56dim NK cells and expansion of $\mathrm{FcR} \gamma$-CD3 $\zeta+\mathrm{NK}$ cells started post-HSCT 150 days. Sequential results of NK cytotoxicity, NK cell-mediated antibody-dependent cellular cytotoxicity (NK-ADCC), and NK-Interferon-gamma (NK-IFN $\gamma$ ) production for 180 days demonstrated delayed recovery and decreased levels in the CMV disease group compared with the other groups. The results within 1 month after CMV viremia also showed a significant decrease in NK function in the CMV disease group compared to the CMV reactivation group. It suggests that NK cells' maturation and cytotoxic/IFN $\gamma$ production contributes to CMV protection, thereby revealing the NK phenotype and functional NK monitoring as a biomarker for CMV risk prediction, especially CMV disease.
\end{abstract}

Keywords: cytomegalovirus; hematopoietic stem cell transplantation; acute myeloid leukemia; NK cells; NK cell-mediated antibody-dependent cellular cytotoxicity; NK subsets; IFN $\gamma$

\section{Introduction}

Hematopoietic stem cell transplantation (HSCT) is a well-established treatment for patients with acute myeloid leukemia (AML) [1]. While allogeneic HSCT from an human leukocyte antigen (HLA)-matched related donor is ideal, alternative approaches, such as HSCT from HLA-matched unrelated donor (MUD) or haploidentical HSCT from the familial mismatched donor (FMD), are proposed for patients with advanced leukemia [2]. HSCT from MUD and FMD has demonstrated 
a higher incidence of CMV viremia and delayed immune constitution compared to HSCT from HLA-matched related donors, suggesting the employment of novel approaches, such as immunotherapy or more aggressive CMV prophylaxis, in these patients [3].

Primary CMV infection usually occurs asymptomatically, but virus infection could be a potentially life-threatening complication in immune-deficient patients [4-6]. After HSCT, patients are vulnerable to CMV infection, which can occur during immunosuppression and proceed to severe CMV disease with high mortality [4,7-9]. The range of CMV infection is wide, ranging from CMV reactivation and presenting mainly as asymptomatic viremia, DNAemia, or antigenemia to CMV end-organ diseases, such as esophagitis, gastroenteritis, hepatitis, retinitis, pneumonia, and encephalitis $[5,10]$. Currently, preemptive therapy-based monitoring of CMV viremia is performed to improve CMV-related outcomes [5]. The range of CMV infection after HSCT can be different because HSCT patients have diverse CMV serostatus, different CMV prophylaxis, conditioning methods, genetic polymorphism, and inconstant post-HSCT immune reconstitution against CMV infection [5,7,9,11,12]. Considering these differences, CMV-specific immunity plays a vital role in controlling CMV reactivation and disease development. Therefore, verification and monitoring of the patient's immune cells can be an important tool for the defense of CMV infection.

Natural killer (NK) cells are the initial lymphocyte population and NK cell precursors experience a maturation process during immune reconstitution after HSCT $[13,14]$. It is well known that NK cells play a crucial role in defense mechanisms against CMV infections before complete recovery of the adaptive immune response, and immune response mediated by NK cells during an early post-HSCT period can contribute towards controlling CMV infection in HSCT patients [13-17]. Previous studies reported that CMV reactivation in HSCT patients promoted NK cell maturation and expansion of $\mathrm{NKG2C}+\mathrm{NK}$ cells with specific function against CMV infection [18-20]. However, NK reconstitution and associated cytotoxic/cytokine- production in controlling the CMV infection, especially severe CMV disease, is not fully clarified in HSCT patients.

In the present study, NK immune responses were monitored in AML patients who received HSCT from MUD or FMD by testing the reconstitution kinetics of NK populations and NK-mediated cytotoxic/cytokine production. We compared the results in HSCT recipients stratified on post-HSCT CMV reactivation, non-reactivation versus CMV disease to evaluate the impact of early NK reconstitution in controlling the severity of CMV disease.

\section{Results}

\subsection{Patient Population}

The clinical characteristics of 58 patients according to the CMV reactivation or CMV disease are shown in Table 1. During post-HSCT 180 days, CMV reactivation (CMV viremia $>1000$ copies $/ \mathrm{mL}$ ) was detected in $34(58.6 \%)$ patients, and 11 of them were diagnosed with CMV disease, including pneumonitis or gastrointestinal disease. All the patients were divided into three groups as (1) no CMV infection $(n=24)$, (2) CMV reactivation without CMV disease (CMV reactivation) $(n=23)$, and (3) CMV disease group $(n=11)$. The median time to the first detection of CMV viremia was 35 days (range: 15-94 days) and 28 days (range: 19-90 days) after HSCT in CMV reactivation and CMV disease groups, respectively $(p>0.05)$. Of 58 patients, all grades of acute graft-versus-host disease (aGVHD) were experienced by $35(60.3 \%)$ patients and it was identified that aGVHD was not associated with CMV infection or CMV disease $(p>0.05)$. Patients who received reduced-intensity conditioning treatment were identified to be more susceptible to CMV infection $(p=0.016)$. 
Table 1. Demographics of the studied patients $(n=58)$.

\begin{tabular}{|c|c|c|c|c|}
\hline Characteristics & $\begin{array}{l}\text { All Participants } \\
(n=58)\end{array}$ & $\begin{array}{l}\text { No CMV Infection } \\
(n=24)\end{array}$ & $\begin{array}{l}\text { CMV Reactivation } \\
(n=23)\end{array}$ & $\begin{array}{l}\text { CMV Disease } \\
(n=11)\end{array}$ \\
\hline Median age (range) & $48(18-69)$ & $45(18-61)$ & $48(32-69)$ & $55(22-65)$ \\
\hline Sex; male, $n(\%)$ & $34(58.6)$ & $15(62.5)$ & $14(60.9)$ & $5(45.5)$ \\
\hline \multicolumn{5}{|l|}{ Donor type, $n(\%)$} \\
\hline MUD & $33(56.9)$ & $17(70.8)$ & $12(52.2)$ & $4(36.4)$ \\
\hline FMD & $25(43.1)$ & $7(29.2)$ & $11(47.8)$ & $7(63.6)$ \\
\hline \multicolumn{5}{|l|}{ HSCT intensity, $n(\%)$} \\
\hline MAC & $29(50.0)$ & $17(70.8) *$ & $8(34.8)$ & $4(36.4)$ \\
\hline Non-MAC & $29(50.0)$ & $7(29.2)$ & $15(65.2)$ & 7 (63.6) \\
\hline \multicolumn{5}{|l|}{ GvHD, $n(\%)$} \\
\hline Acute GvHD & $35(60.3)$ & $13(54.2)$ & $13(56.5)$ & $9(81.8)$ \\
\hline Chronic GvHD & $20(34.5)$ & $8(33.3)$ & $7(30.4)$ & $5(45.5)$ \\
\hline \multicolumn{5}{|l|}{ GvHD prophylaxis, $n(\%)$} \\
\hline Tacrolimus & $57(98.3)$ & $23(95.8)$ & $23(100.0)$ & $11(100.0)$ \\
\hline Cyclosporine & $1(1.7)$ & $1(4.2)$ & $0(0.0)$ & $0(0.0)$ \\
\hline \multicolumn{5}{|l|}{ ATG dose, $n(\%)$} \\
\hline $1.25-2.5 \mathrm{mg}$ & $37(63.8)$ & $17(70.8)$ & $14(60.9)$ & $6(54.5)$ \\
\hline $5 \mathrm{mg}$ & $21(36.2)$ & $7(29.2)$ & $9(39.1)$ & $5(45.5)$ \\
\hline \multicolumn{5}{|c|}{ CMV recipient/donor serostatus, $n(\%)$} \\
\hline $\mathrm{R}+/ \mathrm{D}+$ & $55(94.8)$ & $22(91.7)$ & $22(95.7)$ & $11(100.0)$ \\
\hline $\mathrm{R}+/ \mathrm{D}-$ & $2(3.4)$ & $1(4.2)$ & $1(4.3)$ & $0(0.0)$ \\
\hline $\mathrm{R}-/ \mathrm{D}-$ & $1(1.7)$ & $1(4.2)$ & $0(0.0)$ & $0(0.0)$ \\
\hline \multicolumn{5}{|l|}{ Status, $n(\%)$ during the first 6 Mo } \\
\hline Relapse & $3(5.3)$ & $2(8.3)$ & $1(4.5)$ & $0(0.0)$ \\
\hline $\begin{array}{l}\text { Time to CMV viremia detection, } \\
\text { median day (range) }\end{array}$ & $34(15-94)$ & $0(0-0)$ & $35(15-94)$ & $28(19-90)$ \\
\hline
\end{tabular}

Abbreviation: MUD, matched unrelated donor; FMD, familial mismatched donor; HSCT, hematopoietic stem cell transplantation; MAC, myeloablative conditioning; GvHD, graft versus host disease; ATG, anti thymocyte globulin; CMV, cytomegalovirus; AML, acute myeloid leukemia. The chi-squared test was used with $p$-value $*^{*} p<0.05$, No CMV infection group vs. CMV reactivation group).

\subsection{Reconstitution of Immune Cells against CMV Infection after HSCT}

We monitored the absolute number of peripheral white blood cells (WBCs), lymphocytes, CD3+T cells, NK cells, and NKT cells in the three groups. As shown in Figure 1, no difference was observed in the total WBC count. However, the reconstitution of CD3+T cells, NK cells, and NKT cells exhibited a significant decrease in the CMV disease group (Figure 1a) compared to the CMV reactivation or no CMV infection group. Especially, at 60 days post-HSCT, the recoveries of lymphocytes, including $\mathrm{CD} 3+\mathrm{T}$ cell, NK cells, and NKT cells, were significantly reduced in the CMV disease group compared to the CMV reactivation group or no CMV infection group (all $p<0.05$ ).

Subsequently, we examined the recovery of immune cells at 3-4 weeks post-CMV viremia in 34 HSCT patients to investigate whether control of CMV infection induces immune cell redistribution. In patients with progression to CMV disease, a decrease in lymphocyte counts was observed compared to patients with CMV reactivation only $(p=0.033)$ (Figure $1 \mathrm{~b})$. Additionally, we generated the ratios between values obtained from the CMV reactivation/CMV disease group and values from the no infection group, and plotted them from before CMV viremia until 150 days after CMV viremia. The ratio values were below one before onset, and the CMV disease group showed delayed recoveries of immunes cells compared to the CMV reactivation group (Figure A3). 

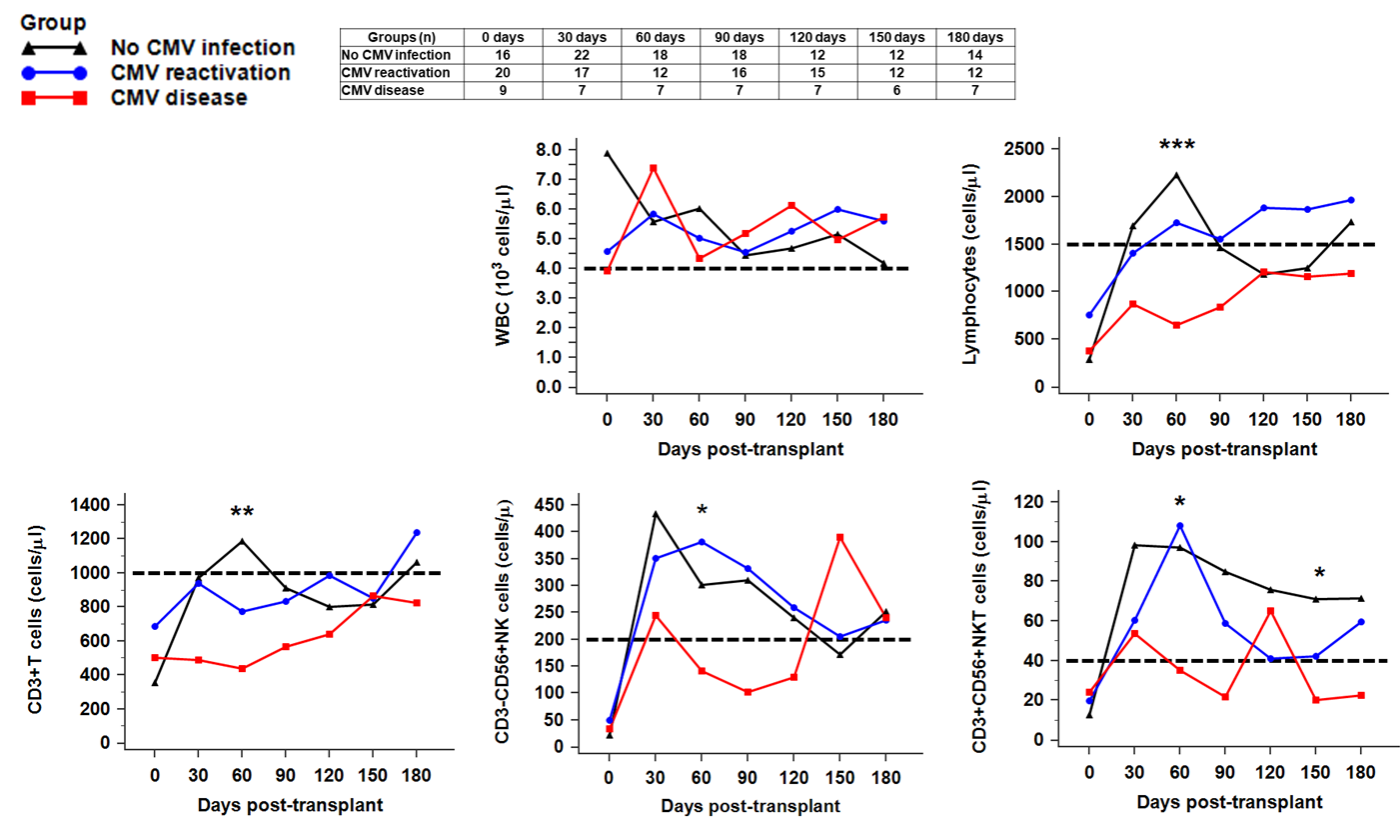

(a)
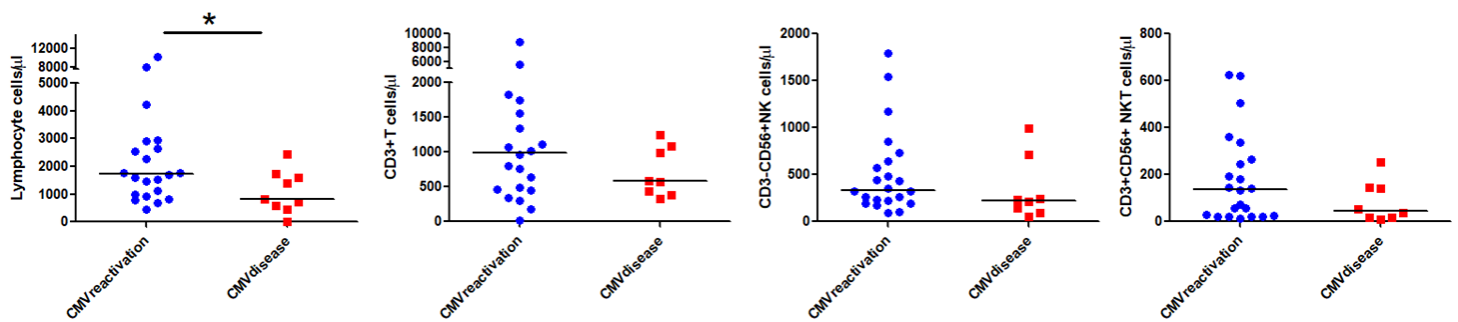

(b)

Figure 1. Reconstitution of immune cells in the three cytomegalovirus (CMV) infection groups after hematopoietic stem cell transplantation (HSCT). (a) Median absolute count of immune cells on 0, 30, 60, $90,120,150$, and 180 days after HSCT are demonstrated. The dashed lines indicate reference values of WBC (4000 cells $/ \mu \mathrm{L})$, lymphocytes $(1500$ cells $/ \mu \mathrm{L}), \mathrm{CD} 3+\mathrm{T}$ cells $(1000$ cells $/ \mu \mathrm{L}), \mathrm{CD} 3-\mathrm{CD} 56+\mathrm{NK}$ cells $(200$ cells $/ \mu \mathrm{L})$, and CD3+CD56+NKT cell (40 cells/ $\mu \mathrm{L})$. Absolute counts of lymphocyte, T cells, NK cells, and NKT cells at post-HSCT 60 days were significantly decreased in the CMV disease group compared to the CMV reactivation group $(p<0.001, p=0.002, p=0.011$, and $p=0.023$, respectively); (b) Immune reconstitution within 1 month after CMV viremia detection. The patients with progression to CMV disease showed decreased lymphocytes count compared to patients with CMV reactivation only $(p=0.033)\left(^{*} p<0.05,{ }^{* *} p<0.01\right.$, and $\left.{ }^{* * *} p<0.001\right)$.

\subsection{Recovery of NK Subsets against CMV Infection}

We distinguished CD56dim and CD56bright NK subsets according to the levels of CD16 and CD56 in the CD3-CD56+NK cells population. Additionally, the levels of FcR $\gamma$-CD3 $\zeta+N K$ subsets ( $\mathrm{g}-\mathrm{NK}$ cells) that are known to be the CMV memory-like NK cells were measured. In a sequential assessment, the recovery of absolute CD56dim, CD56bright, and CMV memory-like FcR $\gamma$-CD3 $\zeta+\mathrm{NK}$ cells count differed significantly among the three groups (Figure 2). Median absolute counts of CD56dim, CD56bright, and FcR $\gamma-\mathrm{CD} 3 \zeta+\mathrm{NK}$ cells on post-HSCT 60 days were significantly lower in patients with CMV disease (all $p<0.05$ ). In addition, the CMV disease group had a significantly delayed recovery of CD56dim NK cells and $\mathrm{FcR} \gamma-\mathrm{CD} 3 \zeta+\mathrm{NK}$ cells as their expansion started after post-HSCT 150 days. Together, these findings suggest that CMV disease delays the expansion of mature NK cells presented by CD56dim and $\mathrm{FcR} \gamma-\mathrm{CD} 3 \zeta+\mathrm{NK}$ cells. In the sequential analysis of the 
ratios (CMV disease or reactivation-to-no infection) during the post-CMV viremia period, the CMV disease group showed delayed reconstitution of NK subsets compared to the CMV reactivation group (Figure A4).

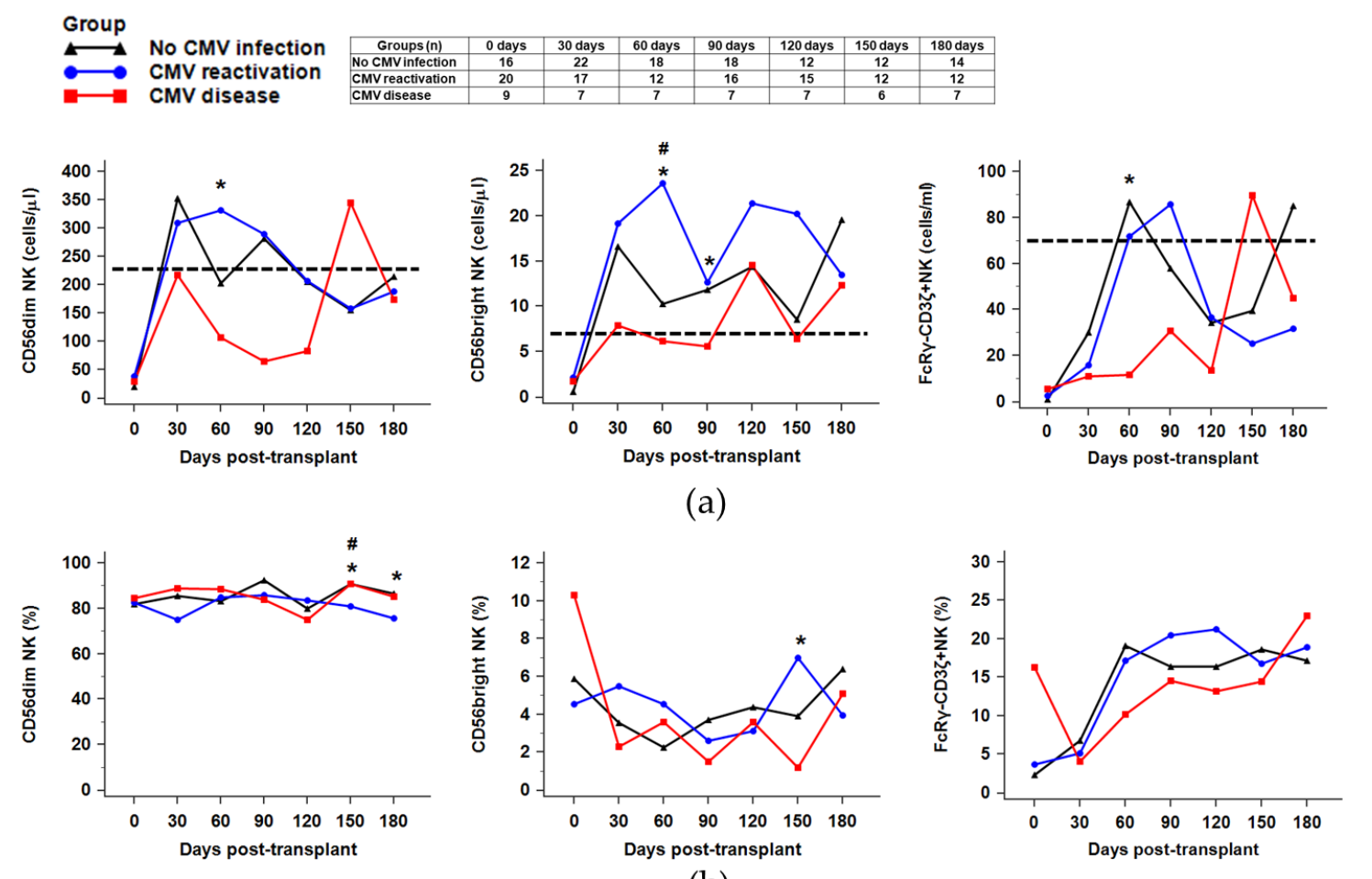

(b)

Figure 2. Sequential analysis of NK cell subsets (CD56dim, CD56bright, and FcR $\gamma$-CD3 $\zeta+N K$ subsets) during 180 days after HSCT ((a) absolute counts, (b) percentage of NK cells). The dashed lines indicate the reference values of CD56dim NK cells (228 cells $/ \mu \mathrm{L}), \mathrm{CD} 56 \mathrm{bright}$ NK cells $(7 \mathrm{cells} / \mu \mathrm{L})$, and $\mathrm{FCR} \gamma-\mathrm{CD} 3 \zeta+\mathrm{NK}$ cells $(70$ cells $/ \mu \mathrm{L})$ on the total NK cell population. The CMV disease group showed delayed recovery and significantly decreased absolute counts of CD56dim, CD56bright, and CMV memory-like FcR $\gamma$-CD3 $\zeta+$ NK cells at post-HSCT 60 days compared to the other groups $(p=0.011$, $p=0.023$, and $p=0.016$, respectively) ( $\left.{ }^{*} p<0.05\right)$. The \# symbols indicate significant differences between the CMV reactivation group and no CMV infection group $(\# p<0.05)$.

In terms of the distribution of the NK subpopulation, the median percentages of CD56dim cells were higher at all the examined time points. On the contrary, the median percentage of CD56bright cells demonstrated an increase during the first 30-60 days in the CMV reactivation group and remained lower thereafter $(<10 \%)$ at all times during the 6 months after HSCT, without any significant differences among the three groups. Whereas the median percentage of the $\mathrm{FcR} \gamma-\mathrm{CD} 3 \zeta+\mathrm{NK}$ population demonstrated an increase after 30 days and remained higher until 180 days after HSCT. However, the level of the $\mathrm{FcR} \gamma-\mathrm{CD} 3 \zeta+\mathrm{NK}$ percentage after HSCT was not different among the three groups at all time points examined.

\subsection{Distribution of NK Receptors (NKG2D, NKG2A, NKG2C)-Positive Population in Response to CMV Reactivation or CMV Disease after HSCT}

We assumed that the lower recovery and reduced count of NK cells and NK subsets after HSCT is associated with the down- or upregulation of NK cell surface receptor expression. Therefore, we additionally analyzed the expression of several surface molecules (NKG2D, NKG2A, NKG2C, and CD57) present on NK cells, and compared the results among the three groups. The absolute numbers of NKG2D+NK and NKG2A+NK started to increase at 30 days after HSCT in all the three groups; whereas, the absolute number or NKG2D+NK cells at post-HSCT 60 days was significantly decreased in the CMV disease 
group compared to the CMV reactivation group ( $p=0.043$ ) (Figure 3$)$. In addition, the absolute count of NKG2D+NK cells recovered to the normal levels in the CMV disease group at post-HSCT 150 days, suggesting a delayed recovery of NKG2D+NK cells. Notably, patients with CMV reactivation or CMV disease displayed expansion of NKG2C+CD57+NK cells at 150-180 days after HSCT, in whom the median percentage of NKG2C+CD57+NK cells were significantly increased from day 30 to 150 after HSCT (patients with CMV reactivation, $2.4 \%$ (day 30) vs. $16.1 \%$ (day 150), $p=0.003$; patients with CMV disease, $6.4 \%$ (day 30 ) vs. $34.2 \%$ (day 150), $p=0.023$ ) (Figure 3b). On the contrary, NKG2C+CD57+NK cells expansion from day 30 to 150 was not observed in HSCT patients without CMV reactivation ( $3.6 \%$ vs. $10.4 \%, p>0.05)$. We also confirmed expansion of the NKG2C+CD57+NK cells in the CMV reactivation and CMV disease groups using the ratios (CMV disease or reactivation-to-no infection) (Figure A5).
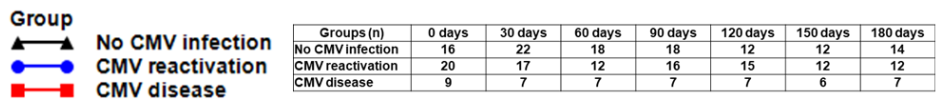
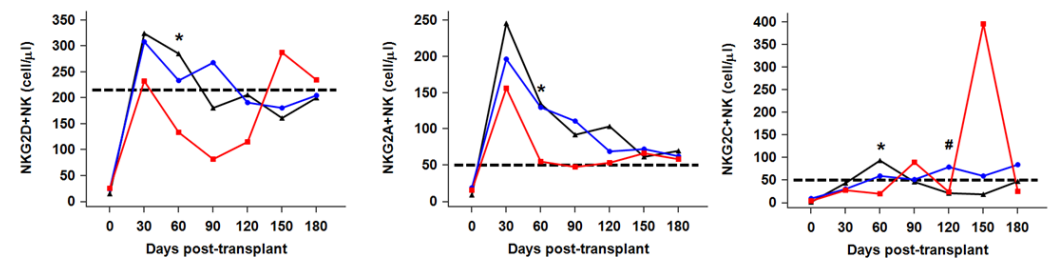

(a)
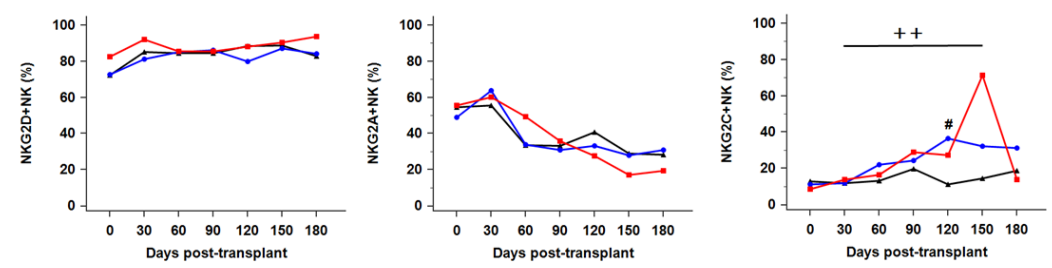

(b)
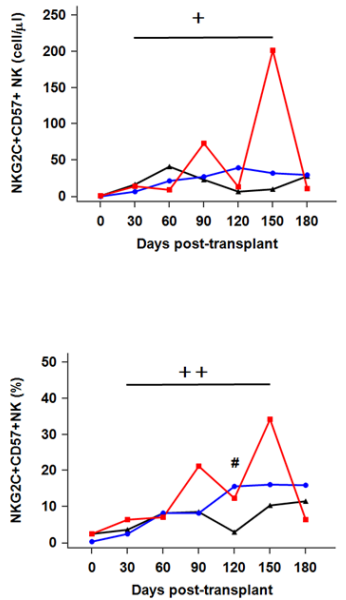

Days post-transplant

Figure 3. Expression of NK cell receptors (NKG2A, NKG2D, NKG2C, and NKG2C/CD57) at 0, 30, 60, 90, 120, 150, and 180 days after HSCT in the three patient groups ((a) absolute counts, (b) percentage of receptor expressing NK cells). The dashed lines indicate reference values of NKG2D+NK cells ( 215 cells $/ \mu \mathrm{L}$ ), NKG2A+NK cells ( 50 cells $/ \mu \mathrm{L}$ ), and NKG2C+NK cells (50 cells $/ \mu \mathrm{L}$ ) on the total NK cell population. The absolute number of NKG2D+NK cells at post-HSCT 60 days was significantly decreased in the CMV disease group compared to the CMV reactivation group $\left({ }^{*} p=0.043\right)$. The \# symbols indicate significant differences between the CMV reactivation group and no CMV infection group (\# $p<0.05$ ). The percentage of NKG2C+CD57+ NK cells expanded at 150-180 days after HSCT in the CMV reactivation and CMV disease group (CMV reactivation, $2.4 \%$ (day 30 ) vs. $16.1 \%$ (day 150 ), $p=0.003$; CMV disease, $6.4 \%$ (day 30) vs. $34.2 \%$ (day 150), $p=0.023)(+p<0.05$ and $++p<0.01$ ).

\subsection{NK Cytotoxicity against CMV Infection after HSCT}

As the CMV disease group showed lower recovery of lymphocytes and delayed expansion of NKG2C+CD57+NK cells after HSCT, we analyzed whether NK function was also decreased in the CMV disease group by testing NK cytotoxicity in response to HLA class I-negative K562 cells (NK-K562 cytotoxicity) and CD20+B lymphoma Raji cells (NK cell-mediated antibody-dependent cellular cytotoxicity; NK-ADCC).

NK-K562 cytotoxicity was recovered (above $40 \%$ ) at day 30 after HSCT in all three groups. The recovered NK function was maintained until 120 days in the CMV reactivation group but not in the CMV disease group (Figure 4a). Comparison of the NK cytotoxicity levels (\%) within 1 month after 
the first viremia detection showed adequate NK function (above 40\%) in 50.0\% of the CMV reactivation group and $33.3 \%$ of the CMV disease group, although statistical significance was not found (Figure $4 \mathrm{~b}$ ).

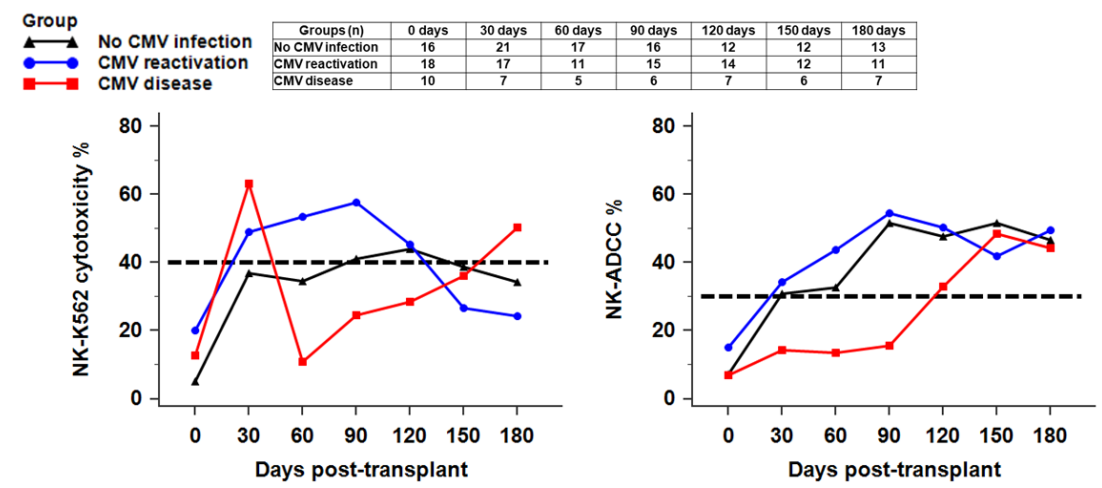

(a)
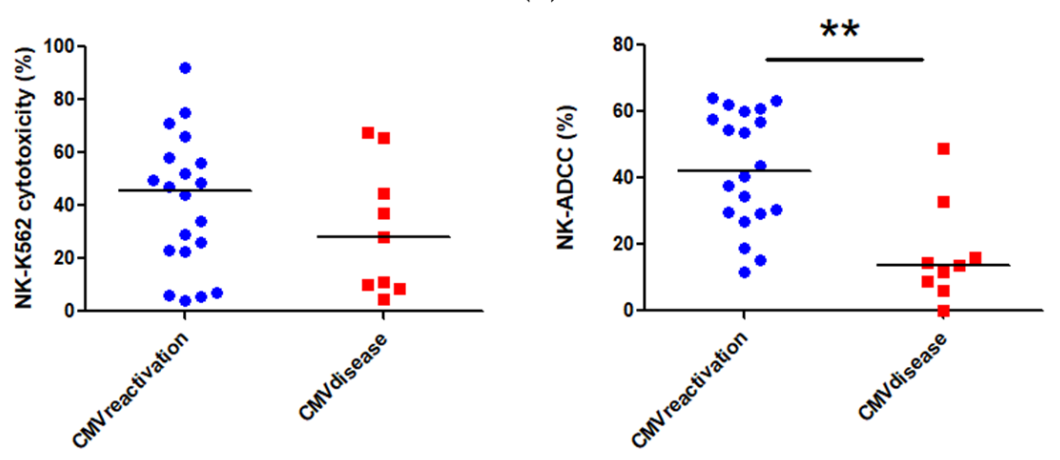

(b)

Figure 4. NK-K562 cytotoxicity and NK-ADCC levels in HSCT patients. (a) Sequential analysis of NK function until post-HSCT 180 days. The dashed lines indicate the reference values of NK-K562 cytotoxicity (40\%) and NK-ADCC (35\%). Both NK-K562 cytotoxicity and NK-ADCC levels were less than normal values at post-HSCT 90-120 days in the CMV disease group, suggesting delayed recovery compared to the other groups. (b) NK function within 1 month after CMV viremia detection in the CMV reactivation and CMV disease group. NK-ADCC levels at less than 1 month after CMV viremia were significantly decreased in patients with CMV disease compared to the patients with CMV reactivation (13.5 [95\% CI: 6.4-30.6] vs. \%, 42.2 [95\% CI: 29.8-57.5], $p=0.002)\left({ }^{* *} p<0.01\right)$.

In terms of NK-ADCC, the HSCT patients without CMV infection and with CMV reactivation only demonstrated satisfactory NK-ADCC results (>30\%) at post HSCT 30 days with sustained NK-ADCC levels until post-HSCT 180 days. On the contrary, the patients who developed CMV disease revealed decreased NK-ADCC levels with delayed recovery until post-HSCT 90 days (Figure 4a). Similarly, the NK-ADCC level at less than 1 month after CMV viremia exhibited a significant decrease in patients with CMV disease compared to the patients with CMV reactivation (13.5 [95\% CI: 6.4-30.6] vs. \%, 42.2 [95\% CI: 29.8-57.5], $p=0.002$ ) (Figure 4b). When we analyzed the ratios of NK-ADCC results (CMV disease or reactivation-to-no infection), the CMV disease group showed the ratio below one until 120 days after CMV (Figure A6b). We also performed multiple regression analysis to evaluate the relationship between NK-ADCC levels and other factors, including acute GvHD, HSCT intensity, and ATG dose. The NK-ADCC results during the early period of viremia were an independent predictor for CMV disease ( $p=0.003$ ). In addition, we also plotted the NK-ADCC levels using the ratios (CMV disease or reactivation-to-no infection) in the subgroup regarding acute GvHD, HSCT intensity, or ATG (Figure A7). There were no significant effects of acute GvHD, HSCT intensity, or ATG on the NK-ADCC levels in the CMV infection group. These outcomes suggest that a lower recovery and decreased NK cytotoxic function influences the development of CMV disease in HSCT patients. 


\subsection{NK Function for IFN $\gamma$ Secretion against CMV Infection after HSCT}

Previous studies demonstrated that $\mathrm{CMV}$ reactivation induces the expansion of IFN $\gamma$, producing NK cells with memory-like features, and these NK cells might contribute towards controlling CMV infection in HSCT patients $[16,20]$. Therefore, we investigated NK activity for IFN $\gamma$ secretion to examine CMV infection, especially whether the development of CMV disease is related to lower NK activity in HSCT patients. The reference value of NK-IFN $\gamma$ levels was defined as above $100 \mathrm{pg} / \mathrm{mL}$.

In HSCT patients without CMV infection, NK-IFN $\gamma$ levels were markedly increased at 30 days after HSCT and gradually decreased until 120 days. The patients with CMV reactivation also demonstrated increased NK-IFN $\gamma$ levels at 30 days after HSCT and sustained levels until 90 days after HSCT. Whereas, patients with CMV disease showed markedly decreased NK-IFN $\gamma$ levels until post-HSCT 120 days (Figure 5a). When we compared NK activity levels for IFN $\gamma$ secretion at post-HSCT 60 days between the CMV disease and CMV reactivation group, the CMV disease group had significantly decreased levels compared with the CMV reactivation group (9.8 [95\% CI: $0.0-384.7] \mathrm{pg} / \mathrm{ml}$ vs. 822.4 [95\% CI: 129.6-2396.6] pg/mL, $p=0.011$ ) (Figure 5a). The results within 1 month after CMV viremia also showed significantly decreased NK-IFN $\gamma$ levels in the CMV disease group compared to the CMV reactivation group (13.7 [95\% CI: $0.0-109.5] \mathrm{pg} / \mathrm{mL}$ vs. 489.7 [95\% CI: $50.8-1164.9] \mathrm{pg} / \mathrm{mL}, p=0.016$ ) (Figures $5 \mathrm{~b}$ and $\mathrm{A} 6$ ).

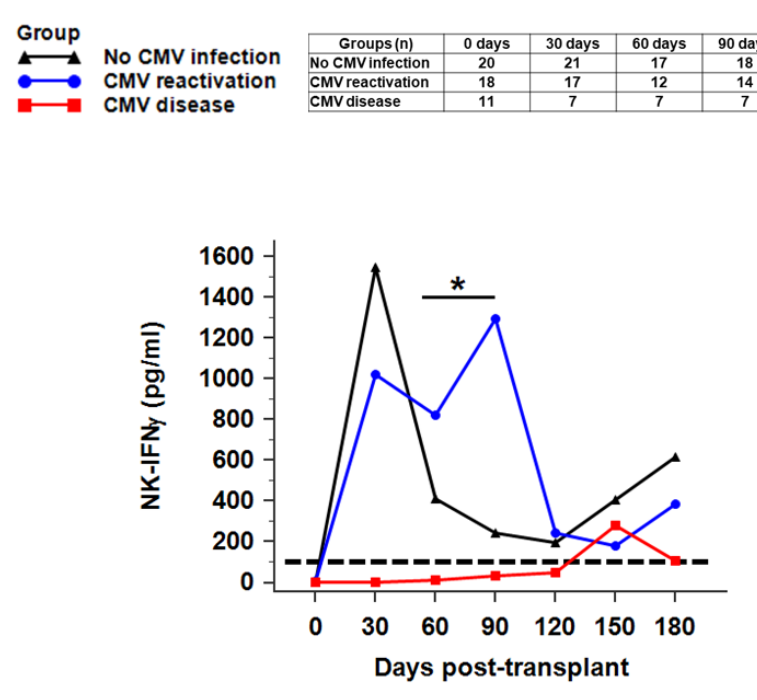

(a)

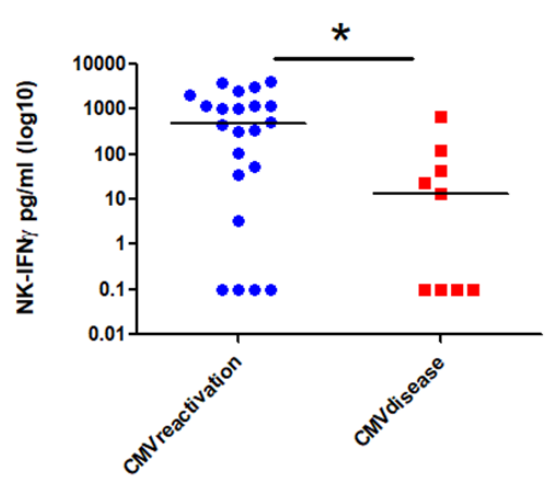

(b)

Figure 5. NK function for interferon-gamma (IFN $\gamma$ ) secretion against CMV infection after HSCT. (a) The CMV disease group showed markedly decreased NK-IFN $\gamma$ levels until post-HSCT 120 days, and had significantly decreased levels at 60 days compared with the CMV reactivation group (9.8 [95\% CI: 0.0-384.7] pg/mL vs. 822.4 [95\% CI: 129.6-2396.6] pg/mL, $p=0.011$ ). (b) NK-IFN $\gamma$ levels at less than 1 month after CMV viremia were significantly decreased in the CMV disease group compared to the CMV reactivation group (13.7 [95\% CI: 0.0-109.5] pg/mL vs. 489.7 [95\% CI: 50.8-1164.9] pg/mL, $p=0.016)\left({ }^{*} p<0.05\right)$. The dashed line indicates the reference value of NK-IFN $\gamma(100 \mathrm{pg} / \mathrm{mL})$. 


\section{Discussion}

In the present study, we monitored the sequential data of 58 AML patients who received HSCT from MUD or FMD. Despite the improvement in CMV prophylaxis and the understanding of NK reconstitution in response to CMV infection, few studies have established FMT/MUD in HSCT patients. Additionally, we demonstrated the functional and phenotypic diversities in NK cells in correlation with CMV disease in HSCT patients. The main purpose of this study was to determine whether NK reconstitution and NK cell function are related to controlling early CMV infection after HSCT.

The absolute count of the immune cells during post-HSCT 180 days was monitored to investigate whether the immune reconstitution is related to CMV infection. The total WBC counts remained above the normal reference level until 180 days after HSCT and no difference was observed among the three groups. As per the results of lymphocyte reconstitution after HSCT, CMV reactivation induced an early recovery of lymphocytes, including T, NK, and NKT cells, at 30-60 days. However, the CMV disease group revealed a slower recovery of lymphocytes than in the CMV reactivation or no infection groups. NK cells start reconstituting within the first weeks after HSCT and are known as firstly reconstituted lymphocytes after HSCT [21-23]. Previous studies reported that CMV reactivation promoted a rapid NK-cell maturation after allo-HSCT [24,25]. On the contrary, Zhang et al. reported that CMV infection after allo-HSCT did not alter the distribution of peripheral NK cells until 100 days post-HSCT [8]. However, they did not distinguish patients with CMV disease from patients with CMV reactivation. Herein, we observed a delayed recovery of $\mathrm{T}$, NK, and NKT cells in only patients with CMV disease. These findings suggest that delayed reconstitution of T, NK, and NKT cells may increase the risks of CMV disease development in MUD or FMD recipients.

The initial results of the study indicated a delayed recovery in lymphocyte reconstitution in the CMV disease group compared to the other groups. Furthermore, we analyzed the immune reconstitution of NK subsets (CD56dim, CD56bright, and FcR $\gamma-\mathrm{CD} 3 \zeta+\mathrm{NK}$ ) and NK receptors (NKG2D, NKG2A, and NKG2C) expressing NK subpopulations. NK cells can be divided into CD56dim NK subsets that cause cytotoxicity and CD56bright NK subsets that are capable of secreting the proinflammatory cytokines [26]. There exist reports on NK subsets specialized for CMV defense, such as the FcR $\gamma-\mathrm{CD} 3 \zeta+\mathrm{NK}$ cells and NKG2C+NK cells [27-31]. It has been reported that CMV infection characterizes the NK cell receptor repertoire and effect on the NK cell development and function $[14,32,33]$. Although the adaptive immunity of NK cells induced by CMV infection may vary among individuals, CMV infection-induced NK cells display clonal expansion, enhanced effector function, and epigenetic modification [34]. In concordance with the previous reports, significantly delayed recovery of CD56dim and FcR $\gamma-\mathrm{CD} 3 \zeta+\mathrm{NK}$ cells was observed in the CMV disease group.

The function of NK cells is regulated by diverse surface receptors that transmit either activating or inhibitory signals into NK cells $[16,35]$. During the patients' CMV interplay, CMV infection shapes the NK cell receptor repertoire and induces the expansion of an NK cell subset expressing the activating NKG2C receptor. Expansion of the NKG2C+NK cell after HSCT has been reported and the NK cell subset has been proposed to play a role in the resolution of CMV infection [13,14]. Cichocki et al. reported a significant expansion of CD56dimCD57+NKG2C+NK cells in response to CMV reactivation [28]. Adams, $n$. M. et al. reported that the level of $\mathrm{NKG} 2 \mathrm{C}+\mathrm{NK}$ reconstitution tends to be lower during the initial HSCT days (15-60 days) with a subsequent increase after 200-360 days post-HSCT [15]. In line with these reports, our study also showed an increased percentage of NKG2C + and CD57+NK cells from day 30 to 150 after HSCT in patients with CMV reactivation and CMV disease. However, the levels of NKG2C + or CD57+NK cells were not different between the CMV reactivation and CMV disease groups $(p>0.05)$. While percentages provide the frequency of positively expressing NK cells at a population level, mean fluorescence intensity (MFI) reflects the molecules per cell for surface receptors expressed by individual NK cells and can adequately characterize NK cells after CMV infection [14]. Thus, further studies are needed to investigate the MFI value of NK cell surface receptors in association with CMV infection. 
CMV reactivation has been reported to promote NK-cell maturation and expansion of CMV-specific NK cells (CMV-induced memory-like NK cells) after HSCT [22,24,36], but studies with an intensive focus on the NK activity and NK cytotoxicity in association with CMV disease after HSCT from MUD or FMD are rare. We analyzed NK function in addition to NK cells reconstitution for 180 days after HSCT in three groups, including no CMV infection, CMV reactivation, and CMV disease.

Herein, sequential results of K562 cytolysis and NK-ADCC for 180 days demonstrated delayed recovery and decreased levels in the CMV disease patient group compared with the other groups. Especially, NK ADCC within a month after CMV viremia showed significantly reduced results in the $\mathrm{CMV}$ disease group compared to the CMV reactivation group. Among the values of the lymphocyte count, NK-ADCC, and NK-IFN $\gamma$ within one month after CMV viremia that were significantly different between the CMV disease and CMV reactivation groups $(p<0.05)$, only the NK-ADCC results during the early period of viremia were an independent predictor for $\mathrm{CMV}$ disease by multiple regression analysis $(p=0.003)$. Zhang et al. demonstrated the response of CD57+NKG2C+FcR $\gamma-\mathrm{CD} 3 \zeta+\mathrm{NK}$ cells to CMV viremia and induction of NK-ADCC in HCMV-infected individuals as a mechanism of NK-ADCC against CMV viremia [37]. Similarly, our results also suggest that delayed maturation or NK cells, especially decreased levels of NKG2C+g-NK cells, may induce decreased ADCC in the CMV disease group.

During primary CMV infection, NKG2C+NK cells expand and produce IFN $\gamma$. Subsequently, adaptive NK cells (CD56dimCD57+ NKG2C + ) increase and become functionally active upon CMV infection [20]. IFN $\gamma$ secretion from the NK cells is caused by the activation of intracellular signal transduction pathways and stimulation with other cytokines [38-41]. We finally investigated IFN $\gamma$ secretion as a marker of NK activity in three groups of patients. The IFN $\gamma$ secretion using NK Vue-Kit was mainly from NK cells, and T cells or NKT cells play only a minor role [42]. Figures 4 and 5 reveal that cytokine secretion and cytotoxic function do not consistently coexist in reconstituting NK cells after HSCT. In our cohort of patients, the CMV disease group showed delayed expansion of the memory NK population of NKG2C $+\mathrm{NK}$ cells along with a delayed display of IFN $\gamma$-producing capabilities. However, the levels of NK-IFN $\gamma$ in CMV reactivation patients remained high for 90 days after HSCT compared to normal patients and CMV disease patients. In concordance with the outcomes of the previous studies, it is proposed that expanded memory-like NKG2C+CD57+NK cells are functionally competent regarding cytokine production and may be involved in the regulation of NK cell's adaptive immunity $[17,43]$. However, we cannot define the precise mechanisms affecting the functional regulation of NK cells in CMV infection. Further studies are needed to gain insights on the intracellular signals and the molecular mechanism responsible for the delayed expansion of NKG2C+NKcells and reduced NK function, especially CD107a degranulation in CMV disease patients after HSCT.

Altogether, our results demonstrate that both NK cells' maturation and cytotoxic/IFN $\gamma$ production can contribute to CMV protection, thereby revealing the NK phenotype and functional NK monitoring as biomarkers for CMV risk prediction, especially in CMV disease. As NK cells play a crucial role in mediating early immunity in HSCT, it is hypothesized that the probability to control NK cell reconstitution and function in HSCT recipients may induce important clinical benefits.

\section{Materials and Methods}

\subsection{Patients}

Fifty-eight adult patients who had high-risk AML and underwent allogeneic HSCT at the Seoul St. Mary's Hospital between August 2015 and November 2018 were enrolled in this prospective cohort study. In the absence of an HLA-matched sibling donor, 33 patients underwent HSCT with HLA matched unrelated (MUD) and 25 patients underwent HSCT with a familial mismatched donor (FMD) with conditioning regimens based on our institution's transplantation protocol [2]. This study was approved by the Institutional Review Board of Seoul St. Mary's Hospital (KC12OIST0814). We received 
written consent from all the patients and collected heparinized whole blood for sequential monitoring of NK reconstitution and NK function tests $(0,30,60,90,120,150$, and 180 days after HSCT). For the CMV prophylaxis, high-dose i.v. acyclovir $(10 \mathrm{mg} / \mathrm{kg} 3$ times a day) was administered from the start of conditioning until engraftment (from days -7 to days +28 ). From the time of neutrophil engraftment to hospital discharge, patients were monitored for CMV infection twice a week with a real-time polymerase chain reaction (PCR)-based assay for CMV DNA using the AccuPower CMV quantitative PCR kit (Bioneer, South Korea). CMV infection was diagnosed according to quantitative real-time PCR (levels (CMV DNA >1000 copies/mL in whole blood). CMV DNA load-guided preemptive therapy and diagnosis of CMV disease were conducted using previously published criteria [44].

\subsection{Immunophenotyping}

Peripheral blood mononuclear cells (PBMCs) were separated from fresh blood samples by Ficoll-Hypaque gradients (Sigma-Aldrich, St. Louis, MO, USA) and processed within $4 \mathrm{~h}$. The reconstitution of NK cells after HSCT was determined by eight-color multiparameter flow cytometry using the following mAbs: anti-CD45-FITC (clone; HI30, BD bioscience, San Diego, CA, USA), anti-CD3-V450 (clone; UCHT1, BD bioscience, San Diego, CA, USA), anti-CD16-V500 (clone 3G8; BD bioscience, San Diego, CA, USA), anti-CD56-PE-Cy7 (clone; B159, BD bioscience, San Diego, CA, USA), anti-NKGD-APC (clone; 1D11, BD bioscience, San Diego, CA, USA), anti-NKG2A-PE (clone; REA110, Miltenyi Biotec, Bergisch Gladbach, Germany), anti-NKG2C-Alexa700 (clone 134591, R\&D Systems Inc., Minneapolis, MN, USA), and anti-CD57-V450 (clone; TB01, ebioscience, San Diego, CA, USA). PBMCs were also intracellularly

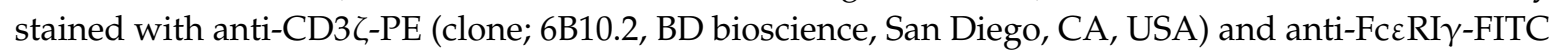
$\left(F_{c} R \gamma\right)($ Millipore, Merck Millipore, Burlington, MA, USA) for the analysis of FceRI $\gamma$-deficient NK cells (g-NK cells). NK cell gating and analyses of the NK subpopulation are shown in Figure A1. Flow cytometry data were collected on an FACS Fortessa instrument (BD bioscience, San Jose, CA, USA), using FlowJo version 10.0.6 software (Tree Star, Ashland, OR, USA).

\subsection{NK Target Cell Lines (K562 and Raji)}

The human erythroleukemia cell line K562 was maintained in Dulbecco's Modified Eagle's Medium (DMEM, Welgene, Gyeongsan-si, Gyengsangbuk-do, Korea) supplemented with 10\% fetal bovine serum, $100 \mathrm{U} / \mathrm{mL}$ of penicillin, and $100 \mu \mathrm{g} / \mathrm{mL}$ of streptomycin (both Gibco-BRL, Waltham, MA, USA). Burkitt lymphoma cell line Raji was cultured in RPMI1640 medium containing 10\% fetal bovine serum, $100 \mathrm{U} / \mathrm{mL}$ of penicillin, and $100 \mu \mathrm{g} / \mathrm{mL}$ of streptomycin (both Gibco-BRL, Waltham, $\mathrm{MA}, \mathrm{USA})$ at $37^{\circ} \mathrm{C}$ in a $5 \% \mathrm{CO}_{2}$ incubator.

\subsection{NK Cytotoxicity}

Target cell lines K562 and Raji were labeled with $2 \mu \mathrm{M}$ CFSE (Thermo Fisher Scientific Inc., New York, NY, USA) to discriminate target cells from effector cells as previously described [45]. Effector peripheral blood mononuclear cells (PBMCs) were incubated with CFSE-labeled target cells at different effecter-to-target (E:T) ratios with 32 and 16 for $4 \mathrm{~h}$ at $37^{\circ} \mathrm{C}, 5 \% \mathrm{CO}_{2}$. PBMCs were cultured in $150 \mu \mathrm{L}$ of culture media and 10,000 target cells were used constantly. The negative control with $\mathrm{K} 562$ and Raji alone was also incubated in each test. To analyze NK-ADCC, Raji cells were additionally treated with $5 \mu \mathrm{M}$ Rituximab (MabThera; Roche, Basel, Switzerland) before incubation with effector cells. After incubation, the cell mixture was stained with $10 \mu \mathrm{L}$ of 7-AAD (Beckman Coulter, Coulter, Fullerton, CA, USA) for 15 min in the dark. Target cells stained with CFSE were analyzed on FACS Fortessa (BD) as shown in Figure A2. NK cytotoxicity (\%) was calculated as [cells positive for both CFSE and 7-AAD/total CFSE positive target cells], after subtracting the spontaneous lysis (\%) in the negative control. 


\subsection{NK-IFN $\gamma$ Secretion Assay}

NK-IFN $\gamma$ secretion assay was performed by enzyme immunoassay using NK Vue-Kit (ATgen, Sungnam, Korea) as described previously [46,47]. Fresh whole blood (1 mL) was attained using tubes containing Promoca. Promoca is a stimulatory cytokine that can specifically stimulate NK cells. The main cell population secreting IFN $\gamma$ after stimulating whole blood with Promoca was NK cells. After incubation at $37^{\circ} \mathrm{C}$ for $20-24 \mathrm{~h}$, cell-free supernatants were harvested and stored at $-70{ }^{\circ} \mathrm{C}$ until the measurement of IFN $\gamma$ levels according to the manufacturer's instructions. Briefly, $50 \mu \mathrm{L}$ of six standards, controls, and samples were incubated in an antihuman IFN $\gamma$-coated plate at room temperature for $2 \mathrm{~h}$ and washed with washing buffer. IFN $\gamma$ conjugate was added and further incubated at room temperature for $1 \mathrm{~h}$. After washing and incubation with $100 \mu \mathrm{L}$ of the substrate at room temperature for $30 \mathrm{~min}$ in the dark, the absorbance value was measured at $450 \mathrm{~nm}$. Concentrations of IFN $\gamma$ were determined with a calibration curve. The measuring range was $0.1-4000 \mathrm{pg} / \mathrm{mL}$ and the total imprecision for two levels of controls was less than the $15 \%$ coefficient of variations.

\subsection{Statistical Analysis}

Results are presented as the median with a 95\% confidence interval (CI). Result graphs are expressed as the median and connecting lines. The between-group differences of the results were compared by Mann Whitney U tests, Kruskal-Wallis tests, and Chi-square tests. A $p$ value of $\leq 0.05$ was considered as statistically significant. Multiple regression analysis (enter model) for CMV disease prediction was conducted with interfering variables, including acute GvHD, HSCT intensity, and ATG dose. Statistical analyses were performed using MedCalc statistical software version 17.6 (MedCalc Software bvba, Ostend, Belgium). Reference values of the NK cells and the NK subset were defined based on previously published data [48,49].

Author Contributions: Conceptualization, E.-J.O. and H.-J.K.; Data curation, B.S.C.; Formal analysis, K.H.P., J.H.R., H.B.; Investigation, H.-J.K.; Methodology, S.Y., J.H.J., K.-H.P.; Supervision, E.-J.O.; Validation, K.H., H.L.; Writing-original draft, K.-H.P. and E.-J.O.; Writing—review \& editing, K.-H.P. and E.-J.O. All authors have read and agreed to the published version of the manuscript.

Funding: This work was supported by the National Research Foundation of Korea (NRF) grant funded by the Korea government (MSIP) (NRF-2017R1A2B4011181) (NRF-2020R1A2B5B01001859), Republic of Korea.

Conflicts of Interest: The authors declare no conflict of interest. The funders had no role in the design of this study, data collection, data analyses, data interpretation, writing of the manuscript, or the decision to publish the results.

\section{Abbreviations}

$\begin{array}{ll}\text { CMV } & \text { Cytomegalovirus } \\ \text { HSCT } & \text { Hematopoietic stem cell transplantation } \\ \text { AML } & \text { Acute myeloid leukemia } \\ \text { NK cell } & \text { Natural killer cell } \\ \text { ADCC } & \text { Antibody-dependent cellular cytotoxicity } \\ \text { IFN } \gamma & \text { Interferon gamma }\end{array}$




\section{Appendix A}

(a)
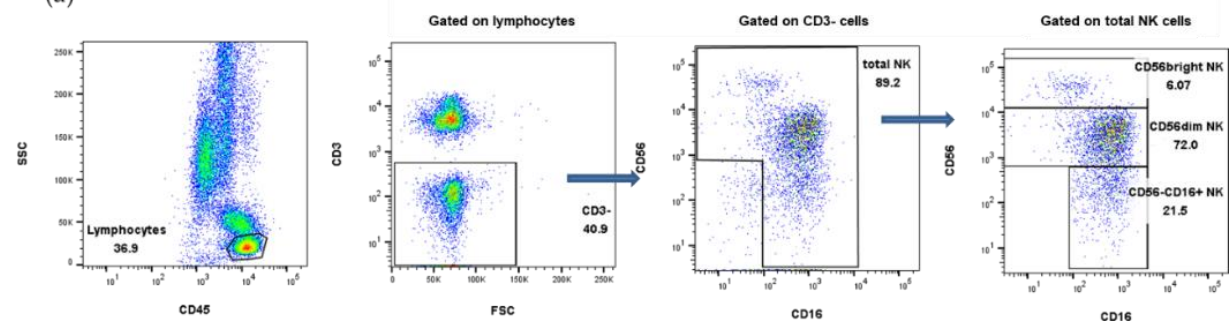

(b)
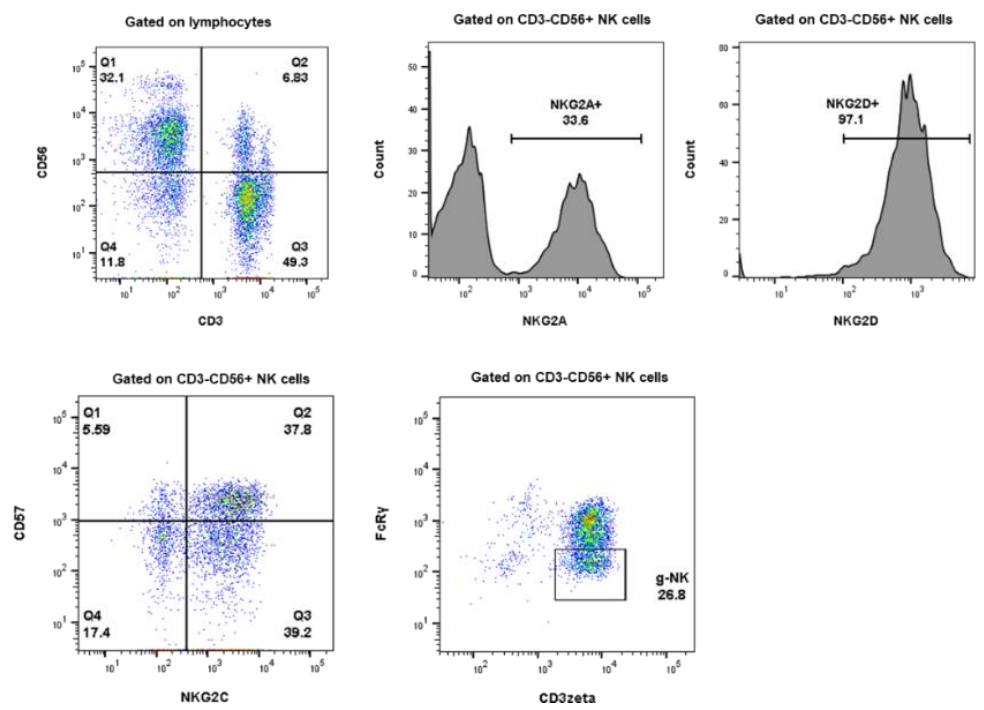

Figure A1. Gating strategy of (a) NK subset (CD56dim NK and CD56bright NK subsets) and (b) NK receptor (NKG2D, NKG2A, CD57/NKG2C+NK, and FcR $\gamma-\mathrm{CD} 3 \zeta+\mathrm{NK})$ analysis.
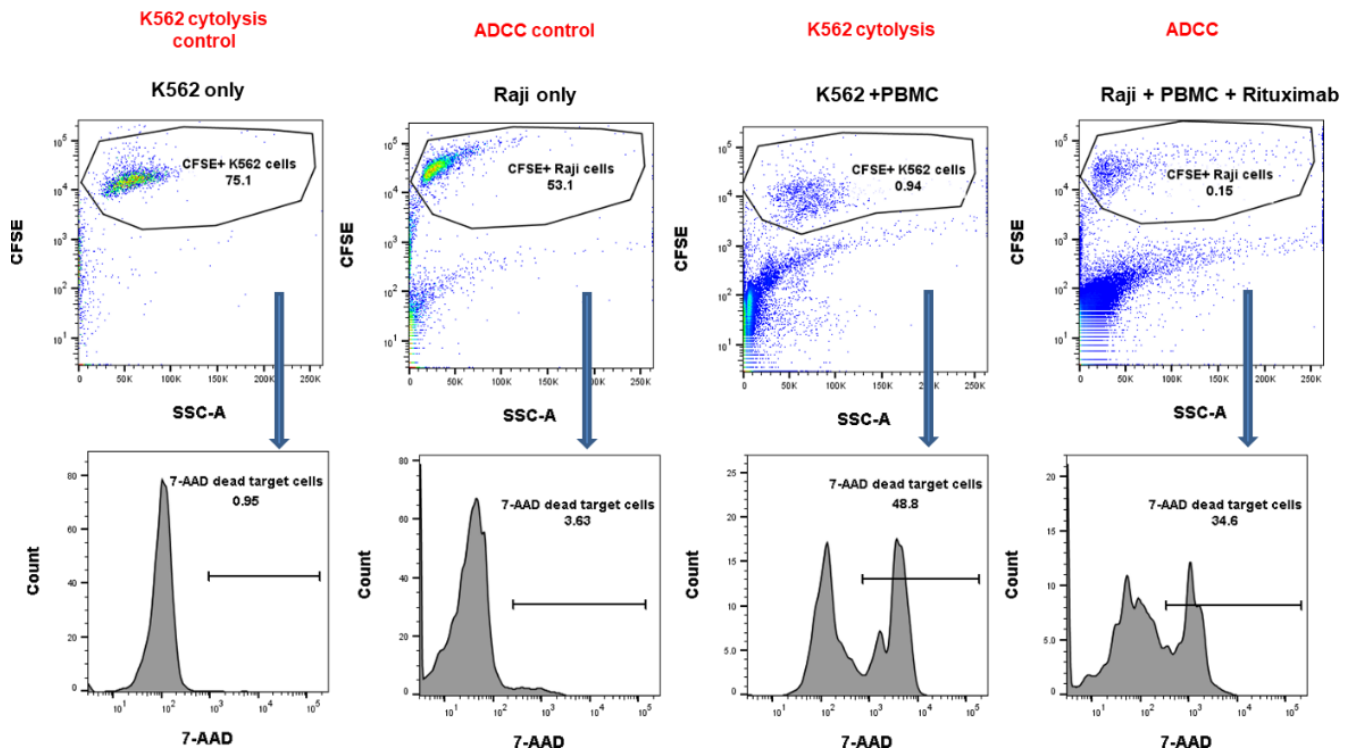

Figure A2. Gating strategy for the NK cytotoxicity test in response to HLA class I-negative K562 cells (NK-K562 cytotoxicity) and CD20+B lymphoma Raji cells (NK cell-mediated antibody-dependent cellular cytotoxicity; NK-ADCC). 
Group

$\longrightarrow$ CMV reactivation

- CMV disease

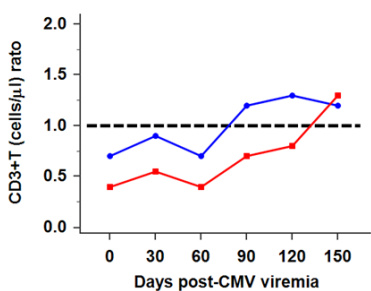

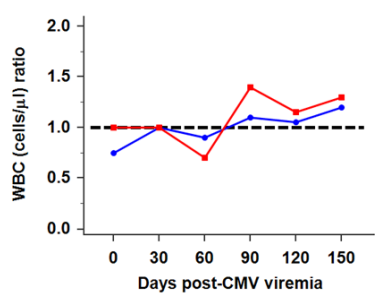
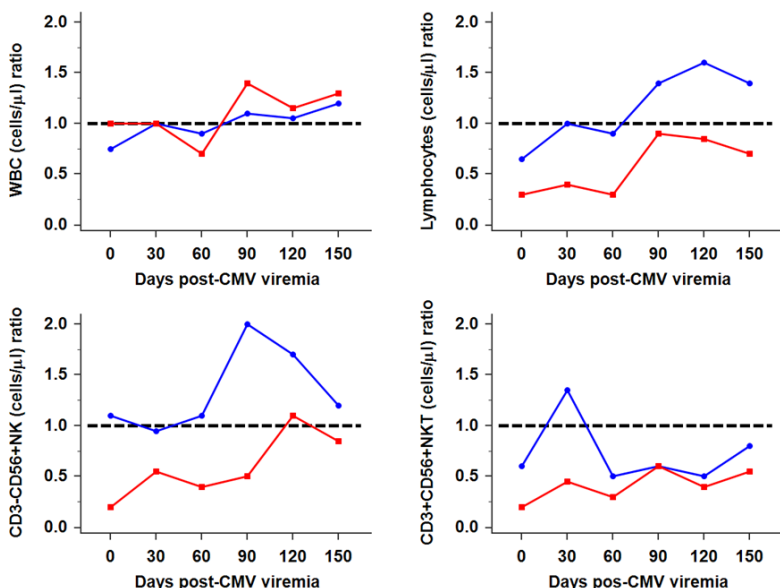

Figure A3. Sequential analysis of immune cells after CMV viremia. The value of immune cells is indicated as ratios between the values obtained from the CMV reactivation/CMV disease group and no infection group.
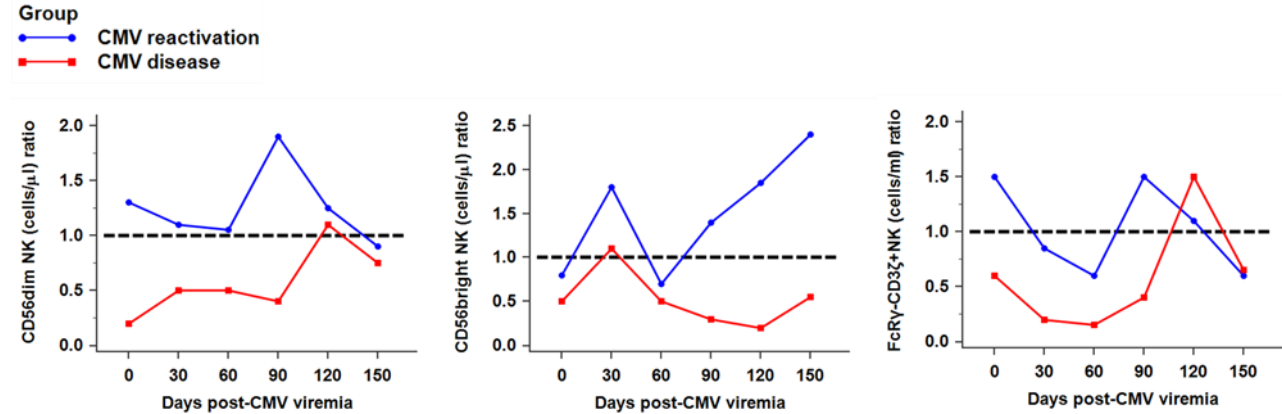

Figure A4. Sequential analysis of NK subsets after CMV viremia. The value of NK subsets is indicated as ratios between the values obtained from the CMV reactivation/CMV disease group and no infection group.
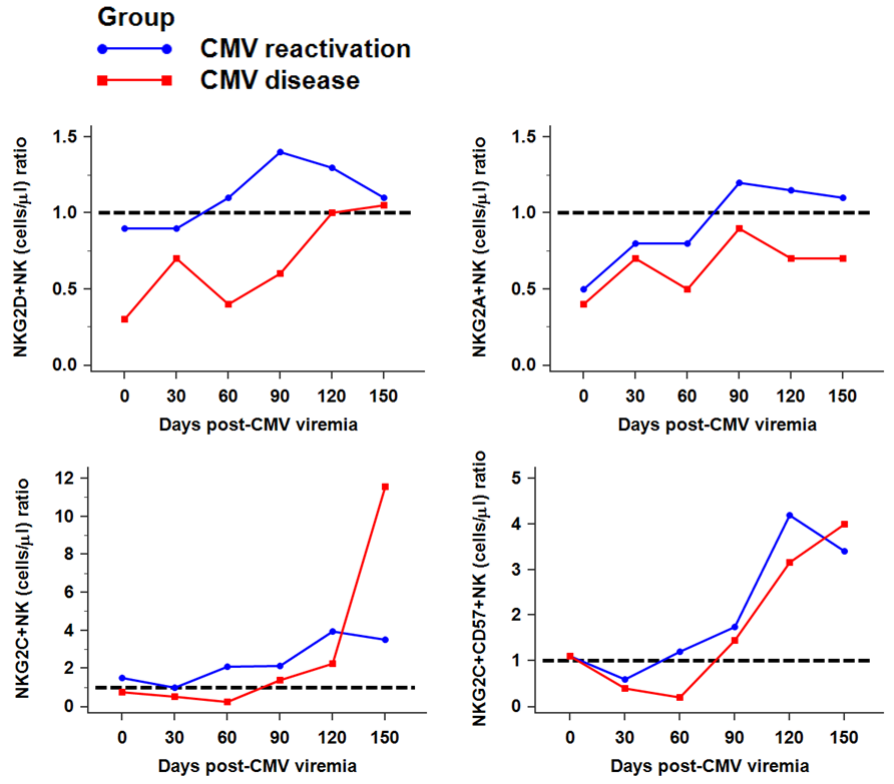

Figure A5. Sequential analysis of absolute counts for NK receptors after CMV viremia. The value of absolute counts is indicated as ratios between the values obtained from the CMV reactivation/CMV disease group and no infection group. 


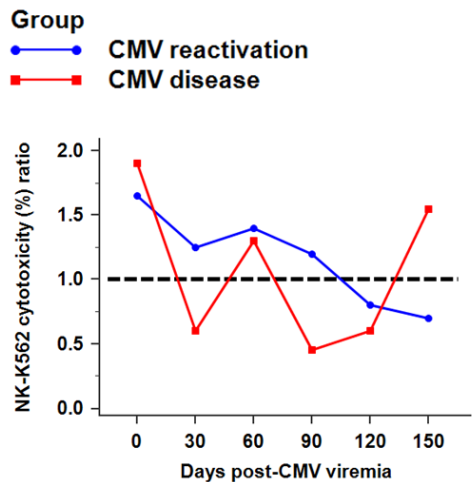

(a)

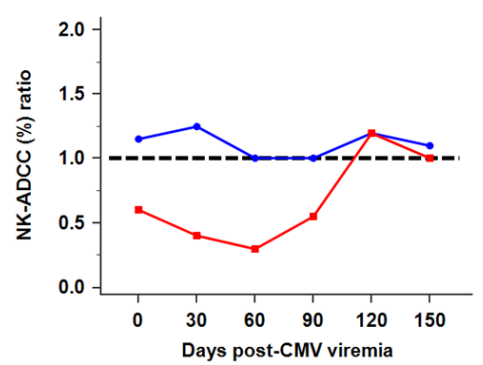

(b)

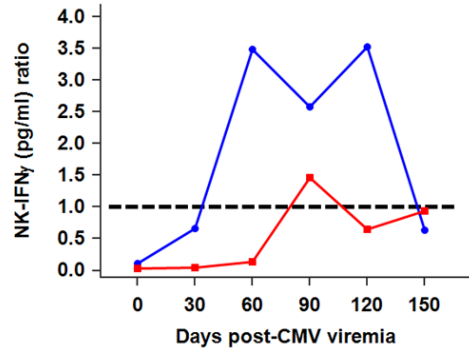

(c)

Figure A6. Sequential analysis of NK function after CMV viremia by NK-K562 cytotoxicity (a), NK-ADCC (b) and NK-IFN $\gamma$ assay (c). The value of absolute counts is indicated as ratios between the values obtained from the CMV reactivation/CMV disease group and no infection group.

\section{Group}

$\longrightarrow$ CMV reactivation

CMV disease
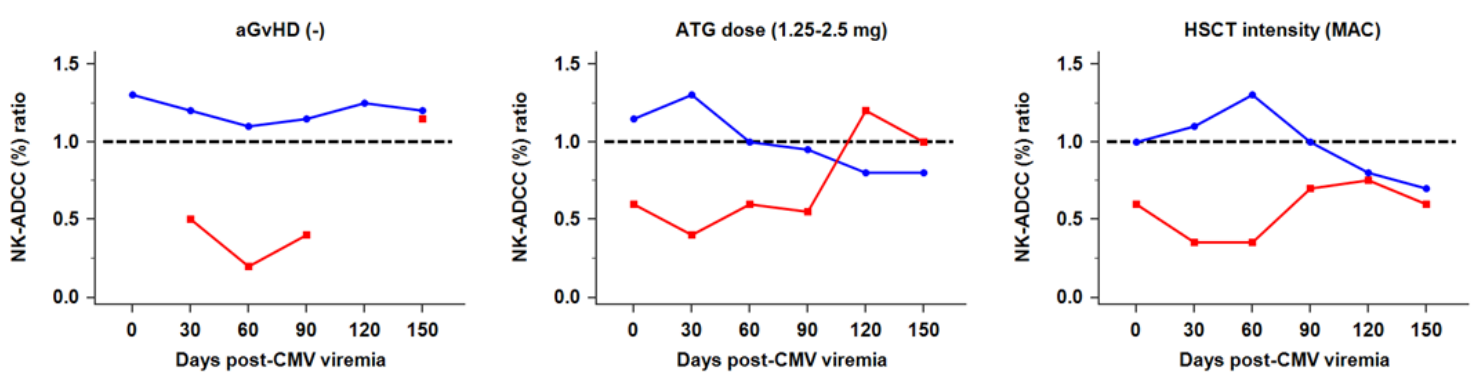

aGvHD (+)
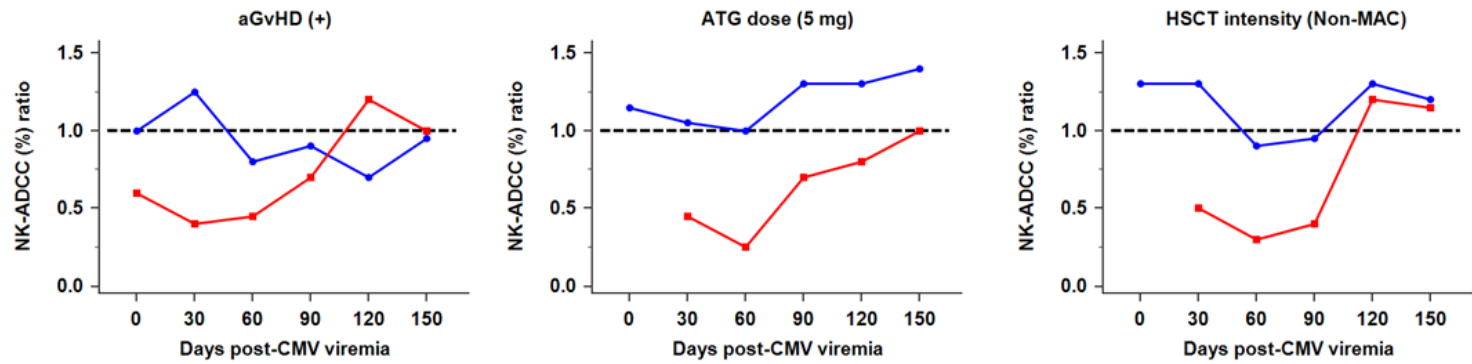

Figure A7. Sequential analysis of NK-ADCC results in subgroups regarding acute GvHD (aGvHD), ATG dose (1.25-2.5 mg vs. $5 \mathrm{mg}$ ), and HSCT intensity (MAC vs. non-MAC). The value of the absolute counts is indicated as ratios between the values obtained from the CMV reactivation/CMV disease group and no infection group.

\section{References}

1. Saber, W.; Opie, S.; Rizzo, J.D.; Zhang, M.J.; Horowitz, M.M.; Schriber, J. Outcomes after matched unrelated donor versus identical sibling hematopoietic cell transplantation in adults with acute myelogenous leukemia. Blood 2012, 119, 3908-3916. [CrossRef]

2. Cho, B.S.; Yoon, J.H.; Shin, S.H.; Yahng, S.A.; Lee, S.E.; Eom, K.S.; Kim, Y.J.; Lee, S.; Min, C.K.; Cho, S.G.; et al. Comparison of allogeneic stem cell transplantation from familial-mismatched/haploidentical donors and from unrelated donors in adults with high-risk acute myelogenous leukemia. Biol. Blood Marrow Transplant. 2012, 18, 1552-1563. [CrossRef]

3. Ruggeri, A.; Ciceri, F.; Gluckman, E.; Labopin, M.; Rocha, V. Alternative donors hematopoietic stem cells transplantation for adults with acute myeloid leukemia: Umbilical cord blood or haploidentical donors? Best Pract. Res. Clin. Haematol. 2010, 23, 207-216. [CrossRef] 
4. $\quad$ Ljungman, P.; Boeckh, M.; Hirsch, H.H.; Josephson, F.; Lundgren, J.; Nichols, G.; Pikis, A.; Razonable, R.R.; Miller, V.; Griffiths, P.D. Definitions of Cytomegalovirus Infection and Disease in Transplant Patients for Use in Clinical Trials. Clin. Infect. Dis. 2017, 64, 87-91. [PubMed]

5. Cho, S.Y.; Lee, D.G.; Kim, H.J. Cytomegalovirus Infections after Hematopoietic Stem Cell Transplantation: Current Status and Future Immunotherapy. Int. J. Mol. Sci. 2019, 20, 2666. [CrossRef] [PubMed]

6. Lee, H.; Park, K.H.; Ryu, J.H.; Choi, A.R.; Yu, J.H.; Lim, J.; Han, K.; Kim, S.I.; Yang, C.W.; Chung, B.H.; et al. Cytomegalovirus (CMV) immune monitoring with ELISPOT and QuantiFERON-CMV assay in seropositive kidney transplant recipients. PLoS ONE 2017, 12, e0189488. [CrossRef] [PubMed]

7. Seggewiss, R.; Einsele, H. Immune reconstitution after allogeneic transplantation and expanding options for immunomodulation: An update. Blood 2010, 115, 3861-3868. [CrossRef] [PubMed]

8. Zhang, J.; Chen, X.; Rong, G.; Xu, T.; Zhao, H.; Chen, D.; Wu, L.; Huang, P.; Wang, F. Peripheral blood lymphocyte responses to cytomegalovirus seropositivity after allogeneic-hematopoietic stem cell transplantation. OncoTargets Ther. 2018, 11, 5143-5150. [CrossRef] [PubMed]

9. Boeckh, M.; Nichols, W.G.; Papanicolaou, G.; Rubin, R.; Wingard, J.R.; Zaia, J. Cytomegalovirus in hematopoietic stem cell transplant recipients: Current status, known challenges, and future strategies. Biol. Blood Marrow Transplant. 2003, 9, 543-558. [CrossRef]

10. Maertens, J.; Lyon, S. Current and future options for cytomegalovirus reactivation in hematopoietic cell transplantation patients. Future Microbiol. 2017, 12, 839-842. [CrossRef]

11. Nam, M.; Shin, S.; Park, K.U.; Kim, I.; Yoon, S.S.; Kwon, T.K.; Song, E.Y. Association of FOXP3 Single Nucleotide Polymorphisms with Clinical Outcomes After Allogenic Hematopoietic Stem Cell Transplantation. Ann. Lab. Med. 2018, 38, 591-598. [CrossRef] [PubMed]

12. Ljungman, P.; Hakki, M.; Boeckh, M. Cytomegalovirus in hematopoietic stem cell transplant recipients. Infect. Dis. Clin. N. Am. 2010, 24, 319-337. [CrossRef] [PubMed]

13. Della Chiesa, M.; Falco, M.; Muccio, L.; Bertaina, A.; Locatelli, F.; Moretta, A. Impact of HCMV Infection on NK Cell Development and Function after HSCT. Front. Immunol. 2013, 4, 458. [CrossRef] [PubMed]

14. Muccio, L.; Falco, M.; Bertaina, A.; Locatelli, F.; Frassoni, F.; Sivori, S.; Moretta, L.; Moretta, A.; Della Chiesa, M. Late Development of FcepsilonRgamma(neg) Adaptive Natural Killer Cells Upon Human Cytomegalovirus Reactivation in Umbilical Cord Blood Transplantation Recipients. Front. Immunol. 2018, 9, 1050. [CrossRef]

15. Adams, N.M.; Geary, C.D.; Santosa, E.K.; Lumaquin, D.; Le Luduec, J.B.; Sottile, R.; van der Ploeg, K.; Hsu, J.; Whitlock, B.M.; Jackson, B.T.; et al. Cytomegalovirus Infection Drives Avidity Selection of Natural Killer Cells. Immunity 2019, 50, 1381-1390.e5. [CrossRef]

16. Jin, F.; Lin, H.; Gao, S.; Wang, H.; Yan, H.; Guo, J.; Hu, Z.; Jin, C.; Wang, Y.; Wang, Z.; et al. Characterization of IFNgamma-producing natural killer cells induced by cytomegalovirus reactivation after haploidentical hematopoietic stem cell transplantation. Oncotarget 2017, 8, 51-63. [CrossRef]

17. Muccio, L.; Bertaina, A.; Falco, M.; Pende, D.; Meazza, R.; Lopez-Botet, M.; Moretta, L.; Locatelli, F.; Moretta, A.; Della Chiesa, M. Analysis of memory-like natural killer cells in human cytomegalovirus-infected children undergoing alphabeta $+\mathrm{T}$ and $\mathrm{B}$ cell-depleted hematopoietic stem cell transplantation for hematological malignancies. Haematologica 2016, 101, 371-381. [CrossRef]

18. Davis, Z.B.; Cooley, S.A.; Cichocki, F.; Felices, M.; Wangen, R.; Luo, X.; DeFor, T.E.; Bryceson, Y.T.; Diamond, D.J.; Brunstein, C.; et al. Adaptive Natural Killer Cell and Killer Cell Immunoglobulin-Like Receptor-Expressing T Cell Responses are Induced by Cytomegalovirus and Are Associated with Protection against Cytomegalovirus Reactivation after Allogeneic Donor Hematopoietic Cell Transplantation. Biol. Blood Marrow Transplant. 2015, 21, 1653-1662.

19. Almehmadi, M.; Flanagan, B.F.; Khan, N.; Alomar, S.; Christmas, S.E. Increased numbers and functional activity of CD56(+) T cells in healthy cytomegalovirus positive subjects. Immunology 2014, 142, 258-268. [CrossRef]

20. Foley, B.; Cooley, S.; Verneris, M.R.; Pitt, M.; Curtsinger, J.; Luo, X.; Lopez-Verges, S.; Lanier, L.L.; Weisdorf, D.; Miller, J.S. Cytomegalovirus reactivation after allogeneic transplantation promotes a lasting increase in educated NKG2C+ natural killer cells with potent function. Blood 2012, 119, 2665-2674. [CrossRef]

21. Ullah, M.A.; Hill, G.R.; Tey, S.K. Functional Reconstitution of Natural Killer Cells in Allogeneic Hematopoietic Stem Cell Transplantation. Front. Immunol. 2016, 7, 144. [CrossRef] [PubMed] 
22. Foley, B.; Felices, M.; Cichocki, F.; Cooley, S.; Verneris, M.R.; Miller, J.S. The biology of NK cells and their receptors affects clinical outcomes after hematopoietic cell transplantation (HCT). Immunol. Rev. 2014, 258, 45-63. [CrossRef] [PubMed]

23. Buhlmann, L.; Buser, A.S.; Cantoni, N.; Gerull, S.; Tichelli, A.; Gratwohl, A.; Stern, M. Lymphocyte subset recovery and outcome after T-cell replete allogeneic hematopoietic SCT. Bone Marrow Transplant. 2011, 46, 1357-1362. [CrossRef] [PubMed]

24. Foley, B.; Cooley, S.; Verneris, M.R.; Curtsinger, J.; Luo, X.; Waller, E.K.; Weisdorf, D.J.; Miller, J.S. NK cell education after allogeneic transplantation: Dissociation between recovery of cytokine-producing and cytotoxic functions. Blood 2011, 118, 2784-2792. [CrossRef]

25. Della Chiesa, M.; Falco, M.; Podesta, M.; Locatelli, F.; Moretta, L.; Frassoni, F.; Moretta, A. Phenotypic and functional heterogeneity of human NK cells developing after umbilical cord blood transplantation: A role for human cytomegalovirus? Blood 2012, 119, 399-410. [CrossRef]

26. Cooper, M.A.; Fehniger, T.A.; Caligiuri, M.A. The biology of human natural killer-cell subsets. Trends Immunol. 2001, 22, 633-640. [CrossRef]

27. Hendricks, D.W.; Balfour, H.H., Jr.; Dunmire, S.K.; Schmeling, D.O.; Hogquist, K.A.; Lanier, L.L. Cutting edge: NKG2C(hi)CD57+ NK cells respond specifically to acute infection with cytomegalovirus and not Epstein-Barr virus. J. Immunol. 2014, 192, 4492-4496. [CrossRef]

28. Cichocki, F.; Cooley, S.; Davis, Z.; DeFor, T.E.; Schlums, H.; Zhang, B.; Brunstein, C.G.; Blazar, B.R.; Wagner, J.; Diamond, D.J.; et al. CD56dimCD57+NKG2C+ NK cell expansion is associated with reduced leukemia relapse after reduced intensity HCT. Leukemia 2016, 30, 456-463. [CrossRef]

29. Hwang, I.; Zhang, T.; Scott, J.M.; Kim, A.R.; Lee, T.; Kakarla, T.; Kim, A.; Sunwoo, J.B.; Kim, S. Identification of human NK cells that are deficient for signaling adaptor FcRgamma and specialized for antibody-dependent immune functions. Int. Immunol. 2012, 24, 793-802. [CrossRef]

30. Rolle, A. Deciphering the biology of NKG2C+ Natural Killer cells. Oncotarget 2015, 6, 19930-19931. [CrossRef]

31. Lopez-Verges, S.; Milush, J.M.; Schwartz, B.S.; Pando, M.J.; Jarjoura, J.; York, V.A.; Houchins, J.P.; Miller, S.; Kang, S.M.; Norris, P.J.; et al. Expansion of a unique CD57(+)NKG2Chi natural killer cell subset during acute human cytomegalovirus infection. Proc. Natl. Acad. Sci. USA 2011, 108, 14725-14732. [CrossRef] [PubMed]

32. Della Chiesa, M.; Falco, M.; Bertaina, A.; Muccio, L.; Alicata, C.; Frassoni, F.; Locatelli, F.; Moretta, L.; Moretta, A. Human cytomegalovirus infection promotes rapid maturation of NK cells expressing activating killer Ig-like receptor in patients transplanted with NKG2C-/- umbilical cord blood. J. Immunol. 2014, 192, 1471-1479. [CrossRef] [PubMed]

33. Della Chiesa, M.; Sivori, S.; Carlomagno, S.; Moretta, L.; Moretta, A. Activating KIRs and NKG2C in Viral Infections: Toward NK Cell Memory? Front. Immunol. 2015, 6, 573. [CrossRef] [PubMed]

34. Cichicki, F.; Schlums, H.; Theorell, J.; Tesi, B.; Miller, J.S.; Ljunggren, H.G.; Bryceson, Y.T. Diversification and Functional Specialization of Human NK Cell Subsets. Curr. Top. Microbiol. Immunol. 2016, 395, 63-94.

35. Lam, V.C.; Lanier, L.L. NK cells in host responses to viral infections. Curr. Opin. Immunol. 2017, 44, 43-51. [CrossRef]

36. Kim, T.W.; Park, S.S.; Lim, J.Y.; Min, G.J.; Park, S.; Jeon, Y.W.; Yahng, S.A.; Shin, S.H.; Lee, S.E.; Yoon, J.H.; et al. Predictive Role of Circulating Immune Cell Subtypes Early after Allogeneic Hematopoietic Stem Cell Transplantation in Patients with Acute Leukemia. Int. J. Stem Cells 2019, 12, 73. [CrossRef]

37. Zhang, T.; Scott, J.M.; Hwang, I.; Kim, S. Cutting edge: Antibody-dependent memory-like NK cells distinguished by FcRgamma deficiency. J. Immunol. 2013, 190, 1402-1406. [CrossRef]

38. Gleason, M.K.; Lenvik, T.R.; McCullar, V.; Felices, M.; O’Brien, M.S.; Cooley, S.A.; Verneris, M.R.; Cichocki, F.; Holman, C.J.; Panoskaltsis-Mortari, A.; et al. Tim-3 is an inducible human natural killer cell receptor that enhances interferon gamma production in response to galectin-9. Blood 2012, 119, 3064-3072. [CrossRef]

39. Fauriat, C.; Long, E.O.; Ljunggren, H.G.; Bryceson, Y.T. Regulation of human NK-cell cytokine and chemokine production by target cell recognition. Blood 2010, 115, 2167-2176. [CrossRef]

40. Trotta, R.; Chen, L.; Ciarlariello, D.; Josyula, S.; Mao, C.; Costinean, S.; Yu, L.; Butchar, J.P.; Tridandapani, S.; Croce, C.M.; et al. miR-155 regulates IFN-gamma production in natural killer cells. Blood 2012, 119, 3478-3485. [CrossRef]

41. Luetke-Eversloh, M.; Cicek, B.B.; Siracusa, F.; Thom, J.T.; Hamann, A.; Frischbutter, S.; Baumgrass, R.; Chang, H.D.; Thiel, A.; Dong, J.; et al. NK cells gain higher IFN-gamma competence during terminal differentiation. Eur. J. Immunol. 2014, 44, 2074-2084. [CrossRef] [PubMed] 
42. Nederby, L.; Jakobsen, A.; Hokland, M.; Hansen, T.F. Quantification of NK cell activity using whole blood: Methodological aspects of a new test. J. Immunol. Methods 2018, 458, 21-25. [CrossRef]

43. Luetke-Eversloh, M.; Hammer, Q.; Durek, P.; Nordstrom, K.; Gasparoni, G.; Pink, M.; Hamann, A.; Walter, J.; Chang, H.D.; Dong, J.; et al. Human cytomegalovirus drives epigenetic imprinting of the IFNG locus in NKG2Chi natural killer cells. PLoS Pathog. 2014, 10, e1004441. [CrossRef]

44. Ljungman, P.; Griffiths, P.; Paya, C. Definitions of cytomegalovirus infection and disease in transplant recipients. Clin. Infect. Dis. 2002, 34, 1094-1097. [CrossRef]

45. Park, K.H.; Park, H.; Kim, M.; Kim, Y.; Han, K.; Oh, E.J. Evaluation of NK cell function by flowcytometric measurement and impedance based assay using real-time cell electronic sensing system. Biomed. Res. Int. 2013, 2013, 210726. [CrossRef] [PubMed]

46. Lee, J.; Park, K.H.; Ryu, J.H.; Bae, H.J.; Choi, A.; Lee, H.; Lim, J.; Han, K.; Park, C.H.; Jung, E.S.; et al. Natural killer cell activity for IFN-gamma production as a supportive diagnostic marker for gastric cancer. Oncotarget 2017, 8, 70431-70440. [CrossRef] [PubMed]

47. Lee, H.; Kim, H.S.; Lee, J.M.; Park, K.H.; Choi, A.R.; Yoon, J.H.; Ryu, H.; Oh, E.J. Natural Killer Cell Function Tests by Flowcytometry-Based Cytotoxicity and IFN-gamma Production for the Diagnosis of Adult Hemophagocytic Lymphohistiocytosis. Int. J. Mol. Sci. 2019, 20, 5413. [CrossRef] [PubMed]

48. Phan, M.T.; Chun, S.; Kim, S.H.; Ali, A.K.; Lee, S.H.; Kim, S.; Kim, S.H.; Cho, D. Natural killer cell subsets and receptor expression in peripheral blood mononuclear cells of a healthy Korean population: Reference range, influence of age and sex, and correlation between NK cell receptors and cytotoxicity. Hum. Immunol. 2017, 78, 103-112. [CrossRef] [PubMed]

49. Baek, H.J.; Kim, D.W.; Phan, M.T.; Kim, J.S.; Yang, J.H.; Choi, J.I.; Lee, J.J.; Shin, M.G.; Ryang, D.W.; Kim, S.K.; et al. Comparison of FcRgamma-Deficient and CD57+ Natural Killer Cells Between Cord Blood and Adult Blood in the Cytomegalovirus-Endemic Korean Population. Ann. Lab. Med. 2015, 35, 423-428. [CrossRef]

(C) 2020 by the authors. Licensee MDPI, Basel, Switzerland. This article is an open access article distributed under the terms and conditions of the Creative Commons Attribution (CC BY) license (http://creativecommons.org/licenses/by/4.0/). 